\title{
Modelo de Gestión Comercial para la Recordación de Marca en una Empresa PYME del Sector Calzado: Contexto COVID-19
}

\section{Commercial Management Model for Brand Awareness in a SME Company of Footwear Sector Before the COVID-19 Context}

\author{
Odar R. Florián Castillo, MBA ${ }^{1}$, Claudia N. Flores Medina, Ingeniera Empresarial ${ }^{2}$ \\ ${ }^{1}$ Universidad Privada del Norte, Perú, odar.florian@upn.edu.pe \\ ${ }^{2}$ Ingeniería Empresarial, Universidad Privada del Norte, claudiafloresmedina2000@ gmail.com
}

\begin{abstract}
The objective of the research was to design a commercial management model for the brand awareness of an SME company in the Footwear Sector, of the city of Trujillo- Peru in 2021 in the context of COVID-19.

The work methodology according to the approach is mixed, applied, prospective. Information gathering techniques from documentary analysis, observation of processes, interviews with the general manager and sales manager. A reliable questionnaire (Cronbach's Alpha of 0.811) and validated by expert judgment was applied to 40 clients (convenience sampling).

The study was developed in three phases: Phase 1 - Strategic Formulation and Planning, with the analysis of the organizational culture, internal and external analysis, commercial analysis, Phase 2 - Strategic design, with the approach of 7 objectives and 8 strategic initiatives and Phase 3 - Evaluation and strategic monitoring, with the design of the Balanced Scorecard with performance evaluation indicators.

Finally, a total investment of $S$ / 76,530 was determined with an annual cost of $S / 71,020$ in 4 years of the project duration with a positive NPV of S / 173,598.16, IRR of $87 \%$ higher than the rate used and $a B$ / $C$ ratio of 1.58, which demonstrates the economic impact and positive viability of the implementation of the designed model in the company under study.
\end{abstract}

Keywords - management model, business management, brand awareness, strategic objective, Covid-19.

Resumen- La investigación tuvo como objetivo diseñar un modelo de gestión comercial para la recordación de marca de una empresa PYME del Sector Calzado, de la ciudad de Trujillo- Perú año 2021 en el contexto de la COVID-19.

La metodología de trabajo según el enfoque es mixta, aplicada, propositiva. Se utilizaron las técnicas de recolección de información del análisis documental, observación de procesos, entrevistas al gerente general y jefe comercial. Un cuestionario confiable (Alpha de Cronbach de 0,811) y validado a juicio de expertos se aplicó a 40 clientes (muestreo por conveniencia).

El estudio se desarrolló en tres fases: Fase 1 - Formulación y Planeamiento estratégico, con el análisis de la cultura organizacional, análisis interno y externo, análisis comercial, Fase 2 - Diseño estratégico, con el planteamiento de 7 objetivos y 8 iniciativas estratégicas y Fase 3 - Evaluación y Seguimiento estratégico, con el diseño del Cuadro de Mando Integral con indicadores de evaluación de desempeño.

Digital Object Identifier (DOI):

http://dx.doi.org/10.18687/LEIRD2021.1.1.10

ISSN: 2414-6390 ISBN: 978-958-52071-9-6
Finalmente, se determinó una inversión total de S/76.530 con costo anual de S/71.020 en los 4 años de duración del proyecto con VAN positivo de S/173.598,16, TIR de 87\% superior a la tasa utilizada $y$ un índice $B / C$ de 1,58, que demuestra el impacto económico y viabilidad positiva de la implementación del modelo diseñado en la empresa en estudio.

Palabras Clave- modelo de gestión, gestión comercial, recordación de marca, objetivo estratégico, Covid-19.

\section{INTRODUCCIÓN}

El objetivo de la investigación es diseñar un modelo de gestión comercial para la recordación de marca de la pyme Calzado D'Niños, teniendo como objetivos específicos:

- Diagnosticar la situación actual de la empresa.

- Analizar los procesos comerciales de la empresa.

- Definir estrategias comerciales para la recordación de marca.

- Establecer métricas e indicadores de control para la evaluación del desempeño de las estrategias planteadas.

- Evaluar el impacto económicos y financieros del modelo de gestión comercial para la recordación de marca.

Para tal efecto, el aporte de la investigación es constatar cómo el diseño de un modelo de gestión comercial determina la recordación de marca de la pyme, por medio de estrategias alineadas a los objetivos comerciales.

La nueva normalidad y los constantes cambios generan la necesidad de ejecutar estrategias de diferenciación y ventaja competitiva en las organizaciones, evidenciándose así, la importancia del desarrollo de la gestión comercial mediante el análisis exhaustivo de los factores del mercado y los clientes, quienes son, los agentes estratégicos de valor para satisfacer necesidades y potenciar la marca.

Ante ello, se vuelve fundamental ejecutar el estudio de la competitividad, cuya importancia radica en que puede ser analizada de diferentes perspectivas y todas ellas, contribuyen a revelar una parte de la ventaja que se genera en una organización [1]. Es la gestión el que es determinante para que las empresas de menor tamaño alcancen su desarrollo y así su permanencia en el mercado, reconocimiento frente a los consumidores y mejoren su competitividad. Las mypes y pymes son clave en la economía mundial, es por ello que se vuelve necesario el poder dedicar horas de trabajo a la gestión, en

$1^{\text {sh }}$ LACCEI International Multiconference on Entrepreneurship, Innovation and Regional Development - LEIRD 2021: "Ideas to Overcome and Emerge from the Pandemic Crisis", Virtual Edition, December 9 - 10, 2021. 
especial en el ámbito comercial. En la medida que las empresas puedan realizar procesos de gestión, utilizar herramientas para identificar problemas, causas y efectos, estarán más conscientes de las alternativas [2]. Si bien las mypes y pymes pueden ser competitivas al ingresar por primera vez a un mercado, sus competidores de mayor tamaño pueden financiar estrategias de mayor alcance para lograr espacios y objetivos propuestos: mientras que muchas veces, para las pymes se convierte en una dificultad el suplir las exigencias que demandan los consumidores [3].

En ese sentido, es donde radica la importancia de la práctica de la Gestión Comercial, que es la actividad que optimizar la relación de apertura de la organización con el mercado y el mundo exterior, involucrando factores como la satisfacción del cliente, nivel de ventas, dosificación de actividades del marketing, participación de mercado, capacitación de recursos humanos, mejora de procesos administrativos; orientando su alineación al logro de la estabilidad rentable, llevando consigo el crecimiento óptimo del negocio. Por ello, en casos como las pequeñas y medianas empresas donde los procesos de planeamiento estratégico no se cuentan formalizados en su conjunto, por la falta de conocimientos y predisposición para invertir tiempo en analizar el mercado para implementar estrategias de ventas, surge la necesidad primordial de ejecutar una adecuada gestión comercial [4]. Con esto, se establece que, la gestión comercial es una de las herramientas más relevantes de la gestión empresarial, por lo que debe potencializarse en cualquier organización que desea alcanzar sus objetivos en función a su mercado meta, siendo fundamental su ajuste en referencia a la ejecución de tareas inmersas en el ámbito de ventas y del marketing, coadyuvando a mejorar la investigación de mercados [5].

Es de suma importancia que las estrategias comerciales se enfoquen en la recordación de la marca frente a la competencia, involucrando las fortalezas y debilidades de la misma y las oportunidades y amenazas del entorno, formando de manera conjunta aspectos de valor que generen ventaja. La recordación de marca busca potenciar y generar un enfoque de dirección de actividades hacia el cliente, buscando ubicar a la empresa y sus productos en la mente del mercado objetivo en referencia al valor añadido, niveles de servicio y la ventaja frente a la competencia, teniendo dichos factores como fuente de reconocimiento [6].

Se denota la importancia de la formulación estratégica en la empresa la cual, probablemente sea uno de los temas más discutidos y debatidos en el mundo empresarial, siendo el factor diferenciador para el éxito, considerado por diferentes generaciones de líderes empresariales [7]. Ante ello, [8] plantea que la estrategia empresarial, en una palabra, es ventaja competitiva que permite que la empresa obtenga una ventaja sostenible sobre sus competidores, alterando las fortalezas relativas de la compañía para distanciarse de sus competidores de la manera más eficiente. Así mismo, [9] considera que la estrategia es una búsqueda deliberada de un plan de acción que desarrolle una ventaja competitiva, donde se sostiene que las diferencias entre la empresa y sus competidores son el fundamento de su ventaja.

Es así, por ejemplo, uno de los casos de éxito más notables es Adidas, una de las marcas deportivas de calzado y ropa, cuyo éxito no se debe sólo a la calidad y originalidad de sus productos, sino también al nivel de sus campañas estratégicas. El más reciente es "Calling All Creators", que cuenta con la participación de grandes estrellas, quienes discuten sobre la importancia de la creatividad, generando un resultado de confianza y seguridad entre la audiencia, llamando la atención de manera distinta a una simple oferta comercial [10]. En medio de la crisis pandémica por la COVID-19, Adidas salvó el año habiendo caído sólo en un $16 \%$ en el 2020, mediante el desarrollo de estrategias comerciales con impacto en las ventas y el e-commerce, aprovechando el "boom" online, logrando agilizar su cadena de suministros [11].

En ese sentido, la industria del calzado es uno de los rubros industriales con mayores cambios en las últimas décadas, habiendo sufrido una desaceleración global, creciendo sólo un 0,6\% respecto al año anterior con una producción de 24,300 millones de pares [12]. En cuanto a la fabricación de calzado nacional, Perú es el cuarto producto de calzado en Sudamérica, estando detrás de Brasil, el segundo productor en el mundo [12]. La producción de calzado en Perú desde 2018, ha registrado una caída debido a la menor fabricación de zapatos, zapatillas y sandalias por la fuerte irrupción de China en el mercado [13], donde se fabrican abundantes cantidades de calzado, con personal poco calificado. Según el Ministerio de la Producción, actualmente, la cadena de fabricación de calzado en el Perú está conformada por más de 5.600 empresas, alrededor del 93\% de ellas son microempresas [14].

El departamento de La Libertad, provincia de Trujillo es la principal zona zapatera del Perú con un gran potencial dinamizador de la economía y generador de empleos, donde operan en promedio 3 mil talleres de cuero y calzado; sin embargo, la crisis por la COVID-19, las fábricas redujeron el $70 \%$ de su fuerza laboral debido a la caída de ventas, con lo que el $50 \%$ de las pymes se encuentran paralizadas, con un alto riesgo de cerrar definitivamente [15].

Calzado D’Niños es una Pyme con más de 30 años de experiencia, dedicada a la producción y comercialización de zapatos, con el objetivo de brindar productos de calidad, diseños exclusivos y atención personalizada; sin embargo, pasa por un periodo de estancamiento, habiendo cerrado el punto de ventas por un tiempo prologando debido a la cuarentena, generando falta de ventas, desconocimiento de la marca por parte de los clientes y poca rentabilidad monetaria. El tiempo de la marca en el mercado no ha generado un impacto notable en la mente de los consumidores, por lo que, para aplacar el estancamiento, es conveniente ejecutar un modelo de gestión comercial alineado al planteamiento de iniciativas estratégicas de valor con métodos de trabajo y actividades a seguir para el logro de los objetivos, siendo el de mayor importancia la recordación de la marca. Si no se implementan planes de contingencia para el aplacamiento de esta problemática, la empresa corre riesgo de quiebra, estando obligada al cierre definitivo, trayendo consigo inestabilidad monetaria para el dueño, su familia y los trabajadores.

Por lo tanto, la motivación de esta investigación es la contribución para el aumento de la recordación de marca de las pymes del sector calzado, siendo uno de los rubros de mayor sustento en la región, para la superación de la crisis sanitaria y económica, supervivencia, proyección a futuro, aumento de la 
rentabilidad e incremento de la satisfacción de las necesidades de los clientes, mediante el diseño de un modelo de gestión comercial con la aplicación de estrategias para obtener ventaja competitiva.

\section{METODOLOGÍA}

La investigación se desarrolla siguiendo la secuencia: Diseño de la investigación, revisión del estado del arte y la estructura del modelo de gestión a diseñar.

A. Diseño de la investigación

\section{A.1 Tipo de investigación}

El estudio tiene enfoque mixto (cuantitativo-cualitativo), con un criterio de estudio aplicado, planificación de recolección de información prospectivo, número de mediciones transversales, intervención observacional del investigador y diseño no experimental.

\section{A.2 Población y muestra}

La población $(\mathrm{N})$ fue de 250 clientes que efectuaron compras entre enero a abril del año 2021 y la muestra (n) de 40 personas obtenidas mediante el muestreo no probabilístico por conveniencia que permite acceder e incluir a los casos acorde a las necesidades del estudio y estando ligada estrechamente con la realidad situacional de la unidad en cuestión [16].

\section{A.3 Procedimiento}

Se aplicó una encuesta validada por juicio de experto, con confiabilidad (Alfa de Cronbach 0,811), para recopilar información sobre factores de evaluación respecto a la recordación de marca (satisfacción del cliente respecto al servicio y producto, identidad de marca, probabilidad de compra, etc.) mediante un cuestionario estructurado. Además, se entrevistó al Gerente General y al Jefe Comercial con una guía de preguntas pre-elaboradas, para obtener información específica sobre la situación a la empresa y el desempeño de la gestión comercial.

Se revisaron los documentos de la empresa (registros de venta), seleccionando datos sobre las variables del estudio en una ficha de registro. Finalmente, se determinaron los indicadores de evaluación para la medición del desempeño del modelo de gestión comercial para la recordación de marca.

\section{B. Revisión del estado del arte}

\section{B.1 Modelo de gestión}

Un modelo de gestión es la aplicación del plan de trabajo empresarial para la ejecución de actividades en las distintas áreas o departamentos, para el cumplimiento de objetivos trazados al inicio del periodo [17].

Así mismo, [18] sostiene que el desarrollo de un modelo de gestión para la innovación debe ser el primer paso de la dirección para llevar a cabo una estrategia con garantía. Estos sistemas deben emanar de la visión de negocio de la empresa y, en particular, de un conocimiento de los procesos que añaden valor a la organización, que incluyan aspectos de comunicación, prestación de servicios y atención al cliente.

Es indispensable considerar que un modelo de gestión es una representación de la realidad empresarial, esto se transforma en un patrón de innovación acorde al entorno. Por ello, se plantea que los modelos y definiciones de la gestión siguen evolucionando. A medida que cambian los valores de la sociedad y organizaciones, se modifican las perspectivas y nacen nuevos modelos de gestión [19].

\section{B.2 Gestión comercial}

La gestión comercial forma parte esencial del funcionamiento de las organizaciones; decisiones relativas a qué mercados acceder, con qué productos, qué política de precios aplicar, cómo desarrollar una sistemática comercial eficaz, forman parte del día a día de las organizaciones, además de ser aspectos que emanan directamente de las decisiones derivadas de la estrategia corporativa [20].

Además, [21] sostiene que la gestión comercial es la que lleva a cabo la relación de intercambio de la empresa con el mercado, comprendiendo desde el estudio de mercado hasta llegar a la venta o colocación del producto a disposición del consumidor, incluyendo las estrategias de venta u la política de ventas en el ámbito empresarial.

La gestión comercial relaciona estrechamente con el marketing o también llamado, mercadotecnia. Esto debido a que gestiona metodologías para la promoción de un producto y/o servicio que una mype o pyme ofrece. Permite el uso de los medios necesarios y oportunos para la administración de las actividades comerciales [22].

Por otra parte, según [23] la gestión comercial de una empresa es la encargada de administrar y ejercer influencia sobre un resultado o variable comercial de las ventas, lo cual corresponde a las decisiones tomadas sobre los canales de venta o alteración comercial del producto o servicio. Siendo los clientes, el principal sustento de las organizaciones, por lo cual, estas deben emplear y dirigir sus estrategias comerciales hacia la satisfacción de estos [24].

\section{B.2 Procedimiento del modelo estratégico de gestión}

La Fig. 1 muestra el esquema del proceso estratégico propuesto por [25] guiado en base a 3 etapas:

- La primera etapa es la formulación, implica el proceso de planeamiento estratégico seguido por el de organización.

- La segunda etapa es la implementación o dirección estratégica, en la cual los ejes centrales están conformados por los procesos de dirección y coordinación.

- La tercera etapa es la evaluación, donde el foco central es el proceso de control proceso estratégico. Ambos constituyen el control estratégico, se desarrolla desde un inicio.

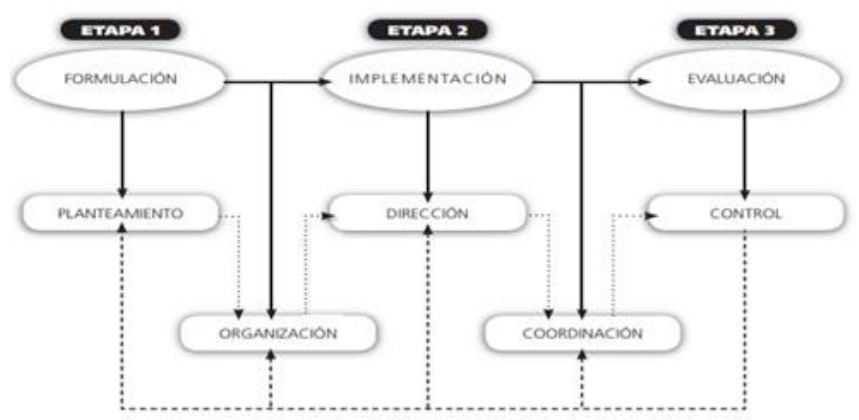

Fig. 1 Etapas del Proceso Estratégico. Fuente [25]

La formulación o planeamiento estratégico, se debe iniciar con la visión y misión, intereses organizacionales, valores, código de ética, evaluación de los factores externos e internos, análisis del sector y de los competidores, la determinación de los objetivos estratégicos y la identificación y selección de las estrategias específicas que, al implementarse, mejoran la competitividad para poder alcanzar la visión trazada [25]. 


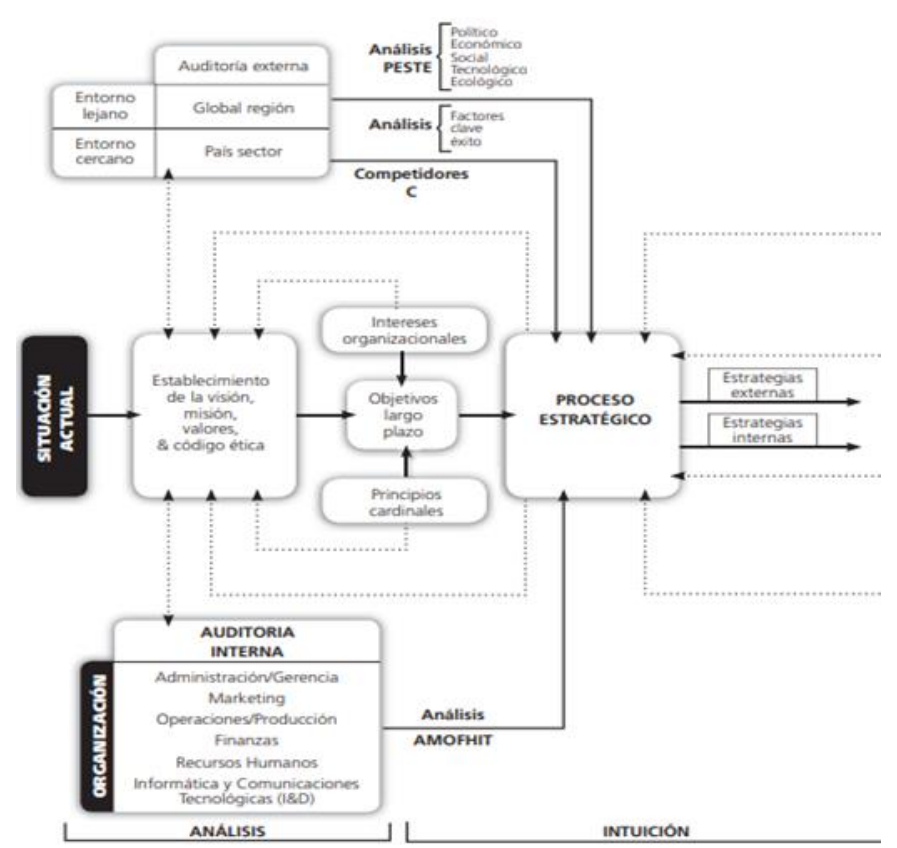

Fig. 2 Planeamiento Estratégico. Fuente [25]

La dirección estratégica comprende seis pasos críticos orientados a coordinar y organizar las estrategias externas e internas elegidas [25].

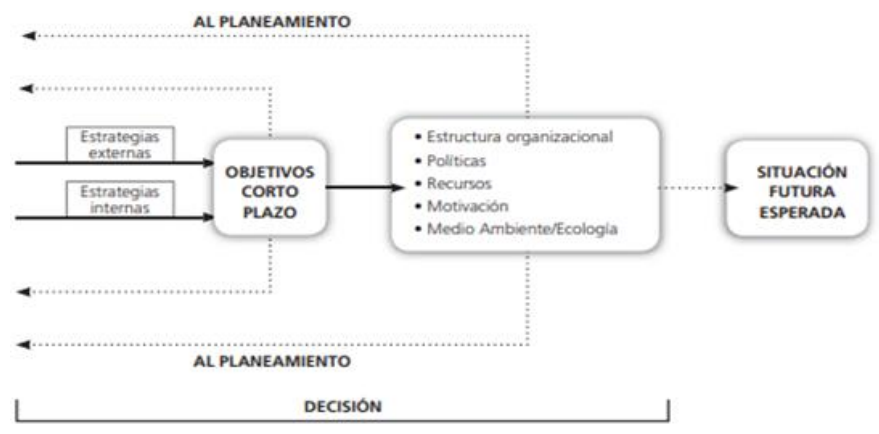

Fig. 3 Direccionamiento Estratégico. Fuente [25]

El control estratégico se pretende cerrar las brechas encontradas entre lo planeado y lo ejecutado. Es una etapa que se lleva a cabo desde el inicio del proceso y está conformada por acciones de supervisión y por los ajustes al plan propuesto. Es pertinente contar con un tablero de control balanceado para evaluar si se están alcanzando los objetivos de corto y largo plazo. Tomar las acciones correctivas para cerrar brechas es el objetivo principal de esta etapa [25].

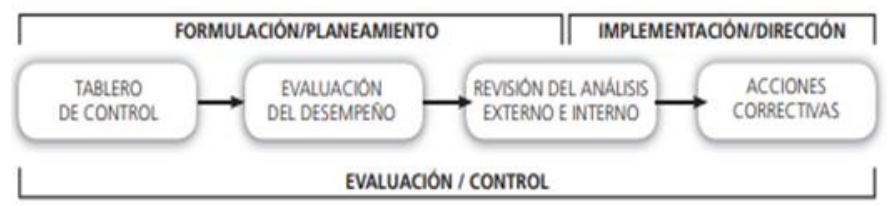

Fig. 4 Control Estratégico. Fuente [25]

La Fig. 5, muestra el modelo del proceso estratégico secuencial (excepto la etapa de evaluación y control que retroalimenta constantemente el proceso); iniciándose con el enunciado de la visión, la misión, los valores y el código de.

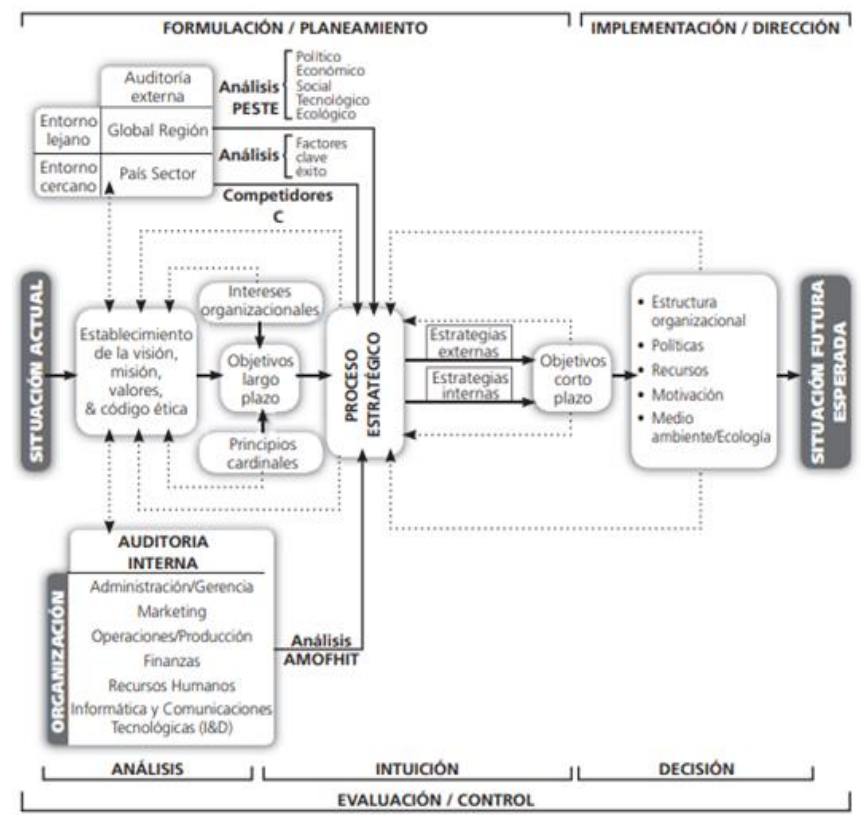

Fig. 5 Modelo Secuencial del Proceso Estratégico. Fuente [25]

ética, para concluir con la revisión de las estrategias, la evaluación y el control de los resultados. Los avances logrados en cada fase constituyen el insumo necesario e indispensable para la ejecución de las etapas siguientes [25]

\section{B.3 Estrategia}

Una estrategia es definida como una elección que involucra a toda la organización y que consiste en seleccionar de entre varias alternativas existentes la más conveniente, de acuerdo con los factores internos y externos de la organización y en tomar decisiones con base en esa elección [26].

Con esto, [25] añade que las estrategias guían a una empresa hacia su visión esperada, logrando alcanzar los objetivos a largo plazo.

\section{B.4 Recordación de marca}

La recordación de marca es el nivel de conocimiento que el consumidor tiene de una marca, es totalmente medible y se refiere a la posición que esta ocupa en la mente de la población. Se obtiene por medio de encuestas y se representa por estadísticas [27]. Toda la información comunicada sobre un producto o servicio específico, será almacenada en la memoria, así como también la experiencia de uso de dicho producto o el nivel de servicio, el resultado de estas dos situaciones en conjunto repercutirá en el recuerdo que tendrá el consumidor. Lo que a su vez actúa sobre el comportamiento de compra mediante la creación, mejor o reforzamiento de sus actitudes. Por tanto, la recordación de marca incrementa la probabilidad de compra, aunque no asegure se adquisición [28].

\section{Estructura del diseño del modelo de gestión}

Se siguió la metodología de [25] para el Modelado Integral de un Proceso Estratégico, donde propone una secuencia de prácticas definidas para el análisis, determinación y control de iniciativas estratégicas. Además, se adaptó el modelo propuesto, teniendo en cuenta los estudios de [29] y [30] cuyas herramientas utilizadas dieron resultados favorables. La propuesta se compone por 3 fases: Formulación y planeamiento 
estratégico donde se ejecuta el análisis de la cultura organizacional, análisis interno y externo y el análisis comercial, Diseño estratégico donde plantea los objetivos estratégicos, iniciativas estratégicas y la decisión estratégica y, finalmente, Evaluación y seguimiento estratégico, donde se plantean los indicadores de gestión bajo el cuadro de mando integral y el análisis de impacto.

TABLA I

ESTRUCTURA DEL MODELO DE GESTIÓN

\begin{tabular}{|c|c|c|}
\hline Ítem & Proceso & Producto / Instrumento \\
\hline \multicolumn{3}{|c|}{ Fase 1: Formulación y Planeamiento Estratégico } \\
\hline \multirow{3}{*}{1} & \multirow{3}{*}{$\begin{array}{l}\text { Análisis de la Cultura } \\
\text { Organizacional }\end{array}$} & Misión \\
\hline & & Visión \\
\hline & & Valores organizacionales \\
\hline \multirow{3}{*}{2} & \multirow{3}{*}{ Análisis Interno } & Cadena de valor \\
\hline & & Análisis AMOFHIT \\
\hline & & Matriz EFI \\
\hline \multirow{4}{*}{3} & \multirow{4}{*}{ Análisis Externo } & Análisis 5 Fuerzas de Porter \\
\hline & & Análisis PESTEL \\
\hline & & Matriz MPC \\
\hline & & Matriz EFE \\
\hline \multirow{2}{*}{4} & \multirow{2}{*}{ Análisis Comercial } & Mapa de procesos \\
\hline & & Flujograma de procesos \\
\hline \multicolumn{3}{|c|}{ Fase 2: Diseño Estratégico } \\
\hline 5 & Direccionamiento & OLP \\
\hline \multirow{6}{*}{6} & \multirow{6}{*}{ Decisión estratégica } & Matriz PEYEA \\
\hline & & Matriz IE \\
\hline & & Matriz GE \\
\hline & & Matriz FODA \\
\hline & & Matriz CPE \\
\hline & & Estrategias seleccionadas \\
\hline \multicolumn{3}{|c|}{ Fase 3: Evaluación y Seguimiento Estratégico } \\
\hline \multirow{2}{*}{7} & \multirow{2}{*}{ Control estratégico } & Cuadro de Mando Integral \\
\hline & & Mapa Estratégico \\
\hline 8 & Análisis económico & Impacto económico, VAN, TIR, $\mathrm{E}$ \\
\hline
\end{tabular}

\section{RESULTADOS}

Se presentan los resultados sustanciales del modelo de gestión comercial planteado.

\section{A. Fase 1: Formulación y planeamiento estratégico}

A.1 Análisis de la cultura organizacional

Mediante las entrevistas con el Gerente General y el Jefe Comercial se determinaron aspectos de la cultura organizacional de Calzado D'Niños, estableciendo:

- Misión: "D' Niños" es una empresa familiar trujillana de producción y venta de calzado para niños; centra sus operaciones en la tendencia y la moda de temporada, buscando reconocimiento comercial basado en el respeto a sus clientes, la pasión por el trabajo, la tolerancia entre compañeros y la responsabilidad social compartida.

- Visión: Ser la empresa trujillana de calzado para niños con mayor reconocimiento por otorgar seguridad y confianza a los padres y madres brindando un producto con precio justo, innovador y de alta calidad, con buenas prácticas de ética profesional y responsabilidad social compartida.

- Valores organizacionales: Pasión por el trabajo, responsabilidad, respecto, responsabilidad social compartida y tolerancia.

\section{A.2 Análisis interno}

\section{- Análisis AMOFHIT}

En la Figura 6 se esquematizó el análisis AMOFHIT donde se determinaron los fortalezas y debilidades de cada área de la organización. Con ello, determinar el desenvolvimiento operativo de la pyme.

Elaboración: Propia

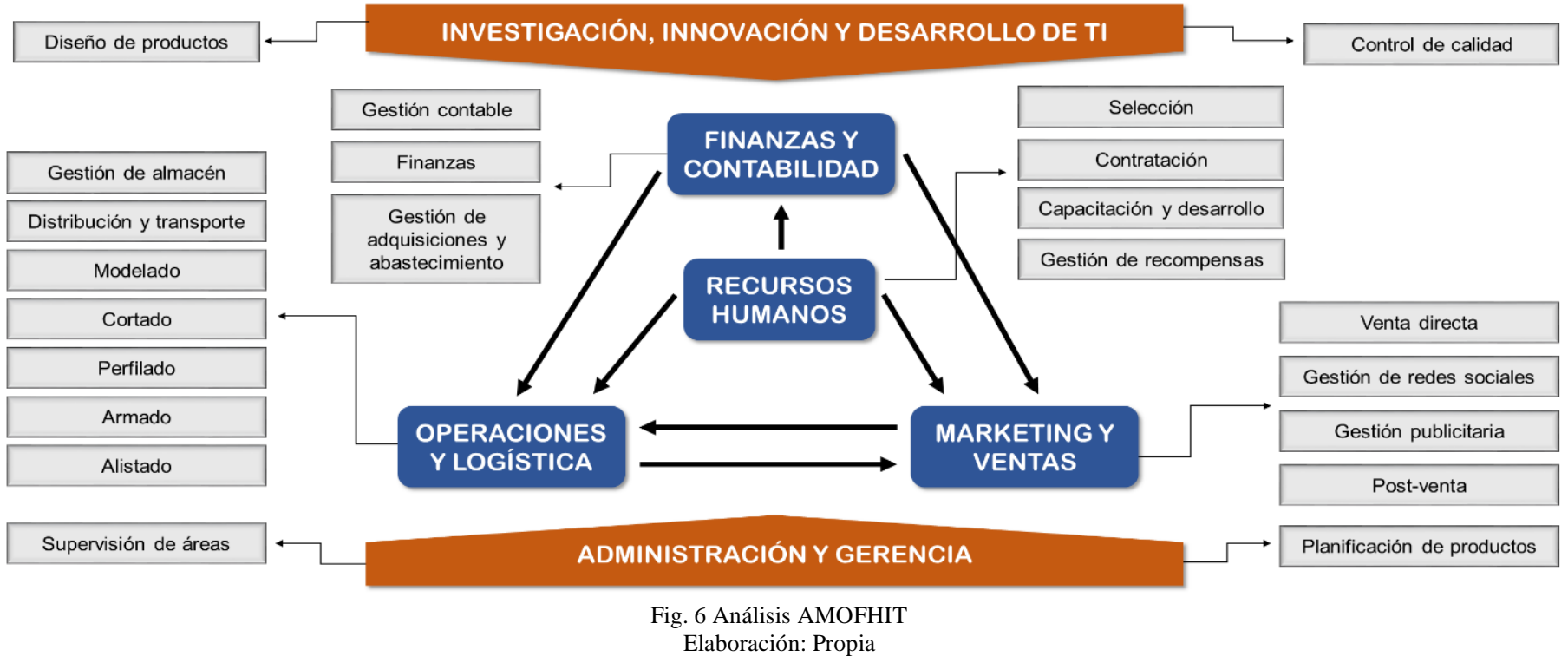

\section{- Matriz EFI}

La unión de las matrices anteriores se centra en la matriz EFI que califica los pesos del 0 al 1 , siendo el más cercano al 0 en menos importante y el más cercano al 1 el más importante; así mismo, las calificaciones son de $1=$ Debilidad mayor, $2=$ Debilidad menor, 3 = Fortaleza menor y $4=$ Fortaleza mayor. La Tabla II muestra las fortalezas con ponderado de 1,96 y 0,61 en las debilidades, evidenciando la tendencia a la mejora. Las debilidades muestran un promedio alto, en la que indica que la empresa posee puntos críticos que la afectan. Ante ello, se obtuvo un total de 2,57, estando por encima de la media del 2,5 pero sólo teniendo un 0,07 de diferencia, lo que hace referencia nuevamente a la situación de estancamiento, con la necesidad de desarrollo de estrategias para su potenciamiento y mejora oportuna. 
TABLA II

MATRIZ DE EVALUACIÓN DE FACTORES INTERNOS (MEFI)

\begin{tabular}{|c|c|c|c|}
\hline Factores Claves de Éxito & Peso & Calificación & $\begin{array}{c}\text { Ponde- } \\
\text { rado }\end{array}$ \\
\hline \multicolumn{4}{|c|}{ FORTALEZAS } \\
\hline Amplia experiencia en el rubro de calzado & 0,05 & 4 & 0,20 \\
\hline Amplia cartera de clientes fieles & 0,06 & 4 & 0,24 \\
\hline Productos con relación calidad-precio & 0,05 & 4 & 0,20 \\
\hline $\begin{array}{l}\text { Productos basados en tendencias y moda de } \\
\text { temporada }\end{array}$ & 0,03 & 3 & 0,09 \\
\hline Servicios de post-venta & 0,05 & 4 & 0,20 \\
\hline Procesos de producción bien estructurados & 0,05 & 4 & 0,20 \\
\hline Proceso de venta con asesoría a clientes & 0,02 & 3 & 0,06 \\
\hline Maquinaria y equipos limpios y ecoamigables & 0,02 & 3 & 0,06 \\
\hline Personal con experiencia y capacitación & 0,03 & 4 & 0,12 \\
\hline $\begin{array}{l}\text { Buena relación con proveedores (poder de } \\
\text { negociación) }\end{array}$ & 0,03 & 3 & 0,09 \\
\hline Buen historial crediticio & 0,03 & 4 & 0,12 \\
\hline $\begin{array}{l}\text { Fuerte cultura organizacional (sólida) con } \\
\text { visión por la mejora y superación }\end{array}$ & 0,06 & 3 & 0,18 \\
\hline $\begin{array}{l}\text { Control de calidad en insumos y modelos } \\
\text { terminados }\end{array}$ & 0,05 & 4 & 0,20 \\
\hline \multicolumn{3}{|c|}{ SUB TOTAL } & 1,96 \\
\hline \multicolumn{4}{|c|}{ DEBILIDADES } \\
\hline $\begin{array}{l}\text { Áreas de trabajo desincronizadas (falta de } \\
\text { comunicación) }\end{array}$ & 0,04 & 1 & 0,04 \\
\hline Demora en procesos de producción & 0,04 & 1 & 0,04 \\
\hline Control de stock deficiente (confusiones) & 0,02 & 2 & 0,04 \\
\hline Falta de planes de contingencia & 0,05 & 1 & 0,05 \\
\hline Poca interacción con clientes en redes sociales & 0,02 & 1 & 0,02 \\
\hline Canal de ventas únicamente presencial & 0,05 & 1 & 0,05 \\
\hline Bajón de ventas por coyuntura sanitaria & 0,06 & 1 & 0,06 \\
\hline Alta dependencia en proveedores & 0,03 & 2 & 0,06 \\
\hline Limitada capacidad (capital) de inversión & 0,05 & 1 & 0,05 \\
\hline $\begin{array}{l}\text { Limitación de personal (pérdida por coyuntura, } \\
\text { realizan } 2 \text { puestos a la vez) }\end{array}$ & 0,04 & 2 & 0,08 \\
\hline $\begin{array}{l}\text { Ejecución de producción de modelos de forma } \\
\text { artesanal }\end{array}$ & 0,02 & 1 & 0,02 \\
\hline Desuso de TI para apoyo en procesos & 0,03 & 2 & 0,06 \\
\hline Alta dependencia en asesor contable & 0,02 & 2 & 0,04 \\
\hline \multirow{2}{*}{\multicolumn{3}{|c|}{ SUB TOTAL }} & $\mathbf{0 , 6 1}$ \\
\hline & & & 2,57 \\
\hline
\end{tabular}

Elaboración: Propia

\section{A.3 Análisis externo}

\section{- Matriz de Perfil Competitivo}

La Tabla III muestra la Matriz MPC donde se indica que la Empresa B es la ganadora, a pesar de poseer menor experiencia en el sector; sin embargo, su adaptación comercial frente a la pandemia fue superior, habiendo implementado medios online para la continuidad de ventas. Por otro lado, D’Niños es superior en publicidad y promociones brindadas al cliente, debido a usa las redes sociales como medio total para realizarlo.

TABLA III.

MATRIZ DE PERFIL COMPETITIVO (MPC)

\begin{tabular}{|c|c|c|c|c|c|c|c|}
\hline \multirow[b]{2}{*}{ Factores claves de éxito } & \multirow[b]{2}{*}{ Peso } & \multicolumn{2}{|c|}{$\begin{array}{l}\text { Calzado } \\
\text { D'Niños }\end{array}$} & \multicolumn{2}{|c|}{$\begin{array}{c}\text { Empresa } \\
\text { A }\end{array}$} & \multicolumn{2}{|c|}{$\begin{array}{c}\text { Empresa } \\
\text { B }\end{array}$} \\
\hline & & نี & 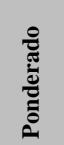 & ن̃ & $\begin{array}{l}\frac{0}{\mathfrak{T}} \\
\frac{\mathfrak{d}}{0} \\
\stackrel{0}{0}\end{array}$ & 苞 & 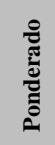 \\
\hline Competitividad de precios & 0,15 & 4 & 0,60 & 3 & 0,45 & 4 & 0,60 \\
\hline Variedad de productos & 0,08 & 4 & 0,32 & 3 & 0,24 & 4 & 0,32 \\
\hline Calidad del producto & 0,20 & 4 & 0,80 & 4 & 0,80 & 4 & 0,80 \\
\hline Calidad de servicio & 0,15 & 4 & 0,60 & 4 & 0,60 & 4 & 0,60 \\
\hline Experiencia en el sector & 0,07 & 4 & 0,28 & 3 & 0,21 & 3 & 0,21 \\
\hline Infraestructura del local & 0,04 & 2 & 0,08 & 2 & 0,08 & 2 & 0,08 \\
\hline Adaptación digital & 0,09 & 1 & 0,09 & 3 & 0,27 & 4 & 0,36 \\
\hline Capacidad del personal & 0,07 & 3 & 0,21 & 3 & 0,21 & 3 & 0,21 \\
\hline Publicidad y promociones & 0,05 & 3 & 0,15 & 2 & 0,10 & 2 & 0,10 \\
\hline Imagen y reputación & 0,10 & 4 & 0,40 & 3 & 0,30 & 4 & 0,10 \\
\hline TOTAL & 1 & & 3,53 & & 3,26 & & 3,68 \\
\hline
\end{tabular}

Elaboración: Propia

\section{- Matriz EFE}

La unión de las matrices anteriores se centra en la matriz EFE que califica los pesos del 0 al 1, siendo el más cercano al 0 en menos importante y el más cercano al 1 el más importante; así mismo, las calificaciones son de $1=$ Nada importante, $2=$ Poco importante, $3=$ Importante y $4=$ Muy importante. La Tabla IV muestra las amenazas con un puntaje de 1,42 y 1,75 en oportunidades, donde se evidencia que se están usando las ventajas del exterior para neutralizar las desventajas, influyen directamente y en gran magnitud teniendo total de 3,17 puntos.

TABLA IV

MATRIZ DE EVALUACIÓN DE FACTORES EXTERNOS (MEFE)

\begin{tabular}{|c|c|c|c|}
\hline Factores Claves de Éxito & Peso & Calificación & $\begin{array}{c}\text { Ponde- } \\
\text { rado }\end{array}$ \\
\hline \multicolumn{4}{|c|}{ OPORTUNIDADES } \\
\hline Cultura de compra a productos en cuero nacional & 0,03 & 3 & 0,09 \\
\hline Proveedores con fuerte nivel de negociación & 0,04 & 4 & 0,16 \\
\hline Competencia con baja calidad y precios altos & 0,05 & 3 & 0,15 \\
\hline $\begin{array}{l}\text { Facilidades crediticias por parte del Estado } \\
\text { (Reactiva Perú) }\end{array}$ & 0,07 & 4 & 0,28 \\
\hline $\begin{array}{l}\text { Creación de planes de salud ocupacional frente a } \\
\text { la COVID-19 }\end{array}$ & 0,03 & 3 & 0,09 \\
\hline Auge del apoyo a emprendimiento locales & 0,04 & 3 & 0,12 \\
\hline $\begin{array}{l}\text { Disponibilidad de softwares libres (TI) para } \\
\text { apoyo de gestión }\end{array}$ & 0,05 & 3 & 0,15 \\
\hline Auge del internet y el e-commerce & 0,06 & 4 & 0,24 \\
\hline Proveedores con insumos ecoamigables & 0,03 & 2 & 0,06 \\
\hline Leyes y políticas de apoyo a mypes y pymes & 0,04 & 3 & 0,12 \\
\hline $\begin{array}{l}\text { Nuevas normativas para reprogramación y/o } \\
\text { fraccionamiento de deudas }\end{array}$ & 0,06 & 4 & 0,24 \\
\hline $\begin{array}{l}\text { Desarrollo de programas de capacitación a pymes } \\
\text { por parte del Estado }\end{array}$ & 0,04 & 2 & 0,08 \\
\hline \multicolumn{3}{|c|}{ SUB TOTAL } & 1,75 \\
\hline \multicolumn{4}{|l|}{ AMENAZAS } \\
\hline Menor poder adquisitivo de la población & 0,06 & 4 & 0,24 \\
\hline Poder de regateo de clientes & 0,03 & 3 & 0,09 \\
\hline Proveedores irresponsables e informales & 0,03 & 2 & 0,06 \\
\hline $\begin{array}{l}\text { Disminución de ventas y demanda (miedo al } \\
\text { contagio o exposición) }\end{array}$ & 0,05 & 4 & 0,20 \\
\hline $\begin{array}{l}\text { Competencia China con bajos precios y alta } \\
\text { capacidad productiva }\end{array}$ & 0,04 & 3 & 0,12 \\
\hline $\begin{array}{lccc}\begin{array}{l}\text { Restricciones } \\
\text { (cuarentena, toque de queda, etc.) }\end{array} & \text { gobierno } \\
\end{array}$ & 0,02 & 2 & 0,04 \\
\hline $\begin{array}{l}\text { Competencia con mayor capital de inversión y } \\
\text { desarrollo de innovación }\end{array}$ & 0,04 & 3 & 0,12 \\
\hline Inestabilidad política (cambio de gobierno) & 0,04 & 3 & 0,12 \\
\hline Crisis económica en el país & 0,05 & 4 & 0,20 \\
\hline Inflación del tipo de cambio & 0,03 & 3 & 0,09 \\
\hline $\begin{array}{l}\text { Maquinaria de última generación muy } \\
\text { contaminante y con costo elevado }\end{array}$ & 0,02 & 2 & 0,04 \\
\hline Aumento de Remuneración Mínima Vital & 0,05 & 2 & 0,10 \\
\hline \multirow{2}{*}{\multicolumn{3}{|c|}{ SUB TOTAL }} & 1,42 \\
\hline & & & 3,17 \\
\hline
\end{tabular}

Elaboración: Propia

\section{A.4 Análisis comercial}

TABLA V

ANÁLISIS DE PROCESOS COMERCIALES

\section{Deficiencias \\ Aciertos}

\begin{tabular}{|l|l|}
\hline \multicolumn{1}{|c|}{ Deficiencias } & \multicolumn{1}{|c|}{ Aciertos } \\
\hline $\begin{array}{l}\text { Existe poca interacción con clientes por } \\
\text { medio de redes sociales }\end{array}$ & $\begin{array}{l}\text { Existe una amplia cartera de clientes } \\
\text { fieles }\end{array}$ \\
\hline El canal de ventas es únicamente presencial. & $\begin{array}{l}\text { Productos se ejecutan bajo la relación } \\
\text { calidad-precio }\end{array}$ \\
\hline $\begin{array}{l}\text { Todos los registros se elaboran de forma } \\
\text { manual. }\end{array}$ & $\begin{array}{l}\text { Existe un servicio de post-venta para } \\
\text { fidelizar a los clientes }\end{array}$ \\
\hline $\begin{array}{l}\text { La proyección de ventas se ejecuta con base } \\
\text { a la experiencia, más no por un medio }\end{array}$ & $\begin{array}{l}\text { Proceso de ventas con asesoramiento } \\
\text { constante a clientes. }\end{array}$ \\
\hline $\begin{array}{l}\text { Existencia de planes estratégico para } \\
\text { posicionamiento, reconocimiento y y } \\
\text { fidelización de clientes. }\end{array}$ & $\begin{array}{l}\text { Capacitación constante a equipo } \\
\text { comercial. }\end{array}$ \\
\hline $\begin{array}{l}\text { No se cuenta con indicadores de evaluación } \\
\text { de desempeño. }\end{array}$ & $\begin{array}{l}\text { Innovación constante en productos en } \\
\text { base a moda de temporada. }\end{array}$ \\
\hline Elaboración: Propia & \multicolumn{2}{|l}{} \\
\hline
\end{tabular}

Elaboración: Propia

La Tabla V denota las deficiencias y aciertos presentados del análisis de los procesos comerciales presentados en la Figura 7.

$1^{\text {sh }}$ LACCEI International Multiconference on Entrepreneurship, Innovation and Regional Development - LEIRD 2021: "Ideas to Overcome and Emerge from the Pandemic Crisis", Virtual Edition, December 9 - 10, 2021. 


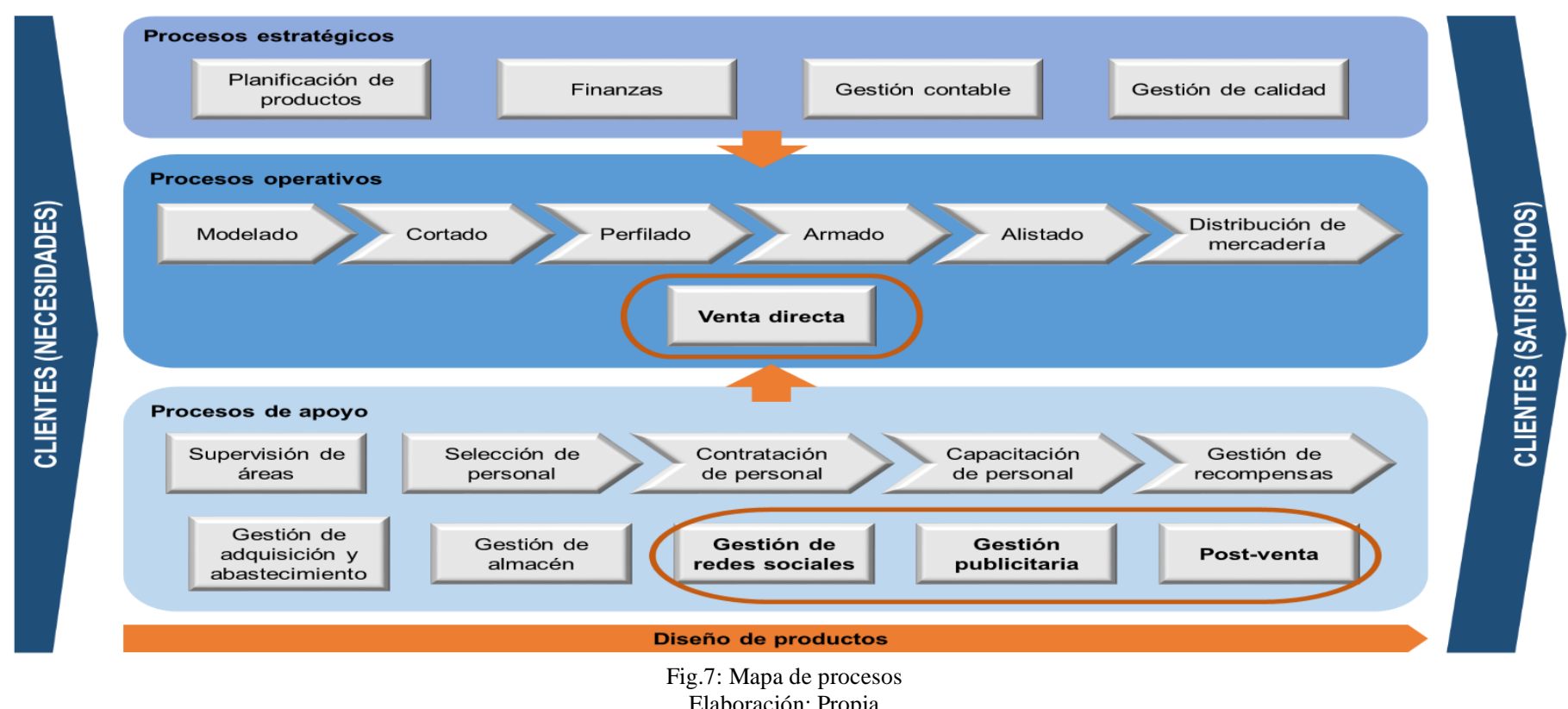

\section{B. Fase 2: Diseño estratégico \\ B.1 Direccionamiento}

TABLA VI

OBJETIVOS A LARGO PLAZO (OLP)

\begin{tabular}{|c|c|c|c|c|}
\hline $\mathbf{N}^{\circ}$ & Objetivo & Meta & Tiempo & Relevancia \\
\hline $\mathrm{O} 1$ & $\begin{array}{l}\text { Aumentar las ventas } \\
\text { efectuadas }\end{array}$ & $15 \%$ & \multirow{7}{*}{$\begin{array}{l}\text { Trimestre } 3 \\
\text { del } 2022\end{array}$} & Márgenes de utilidad \\
\hline $\mathrm{O} 2$ & $\begin{array}{l}\text { Aumentar la eficiencia en } \\
\text { las ventas }\end{array}$ & $10 \%$ & & $\begin{array}{l}\text { Calidad del servicio de } \\
\text { ventas }\end{array}$ \\
\hline $\mathrm{O} 3$ & $\begin{array}{l}\text { Incrementar el número de } \\
\text { clientes nuevos }\end{array}$ & $10 \%$ & & $\begin{array}{lll}\begin{array}{l}\text { Alcance } \\
\text { productos }\end{array} & \text { de } & \text { los } \\
\end{array}$ \\
\hline $\mathrm{O} 4$ & $\begin{array}{l}\text { Aumentar la satisfacción } \\
\text { de los clientes }\end{array}$ & $25 \%$ & & $\begin{array}{l}\text { Imagen positiva de la } \\
\text { marca }\end{array}$ \\
\hline O5 & $\begin{array}{l}\text { Incrementar la } \\
\text { probabilidad de compra }\end{array}$ & $15 \%$ & & Índice de ventas \\
\hline O6 & $\begin{array}{l}\text { Aumentar la satisfacción } \\
\text { laboral de colaboradores }\end{array}$ & $65 \%$ & & $\begin{array}{lll}\begin{array}{l}\text { Compromiso de los } \\
\text { colaboradores }\end{array} & \\
\end{array}$ \\
\hline $\mathrm{O} 7$ & $\begin{array}{l}\text { Aumentar el conocimiento } \\
\text { positivo de la marca }\end{array}$ & $15 \%$ & & $\begin{array}{l}\text { Imagen positiva de la } \\
\text { marca }\end{array}$ \\
\hline
\end{tabular}

Elaboración: Propia

La Tabla VI muestra los 7 Objetivos a Largo Plazo (OLP).

\section{B.2 Decisión estratégica}

\section{- Matriz PEYEA}

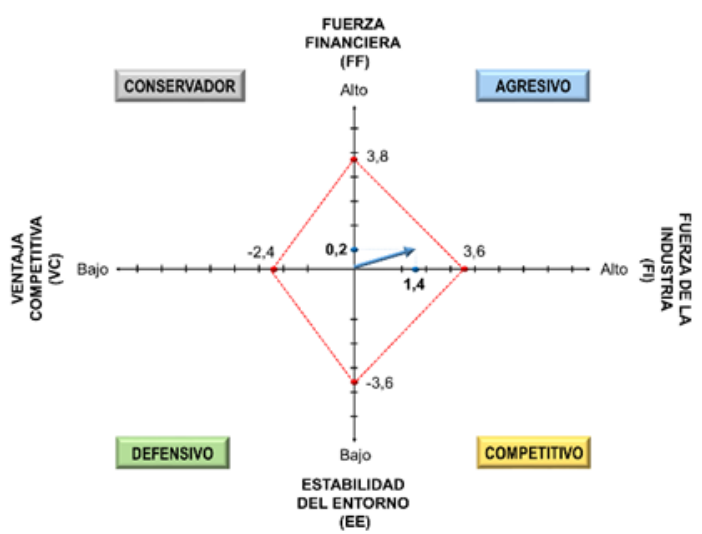

Fig. 8: Matriz de Posición Estratégica y Evaluación de Acción (PEYEA) Elaboración: Propia

La Fuerza Financiera (FF) y Ventaja Competitiva (VC) corresponden a la Posición Estratégica Interna y la Estabilidad del Ambiente (EA) y la Fuerza de la Industria (FI) a la Posición Estratégica Externa. Los pesos van del 1 (bajo) al 6 (alto) para la FF y EI y de - 1 (alto) al -6 (bajo) para la EE y VC. Los valores finales fueron: $\mathrm{EA}(-3,6), \mathrm{FI}(3,6), \mathrm{FF}(3,8)$ y VC $(-2,2)$, estando en el cuadrante "Agresivo", estableciendo que Calzado D’Niños debe utilizar sus fortalezas para contrarrestar sus debilidades y aplacar las amenazas externas. Se evidencia el planteamiento de estrategias agresivas como la diversificación concéntrica, integración vertical, el control de costos, reducción de gastos en ventas, publicidad e investigación y desarrollo.

TABLA VII

POSICIÓN ESTRATÉGICA INTERNA Y EXTERNA

\begin{tabular}{|l|c|l|c|}
\hline \multicolumn{2}{|c|}{ Posición Estratégica Externa } & \multicolumn{2}{c|}{ Posición Estratégica Interna } \\
\hline \multicolumn{1}{|c|}{ Estabilidad del Ambiente } & Peso & \multicolumn{1}{|c|}{ Fuerza Financiera } & Peso \\
\hline Inflación del tipo de cambio & -5 & Retorno sobre la inversión & 4 \\
\hline Variación económica & -5 & Apalancamiento & 6 \\
\hline Presión de competencia & -4 & Facilidades crediticias & 5 \\
\hline Variación de la demanda & -3 & Capital de inversión & 2 \\
\hline Barreras de ingreso al mercado & -2 & Control y manejo contable & 2 \\
\hline Cambios tecnológicos & -3 & Rotación del inventario & 4 \\
\hline \multicolumn{1}{|c|}{ Promedio } & $\mathbf{- 3 , 6}$ & \multicolumn{1}{|c|}{ Promedio } & $\mathbf{3 , 8}$ \\
\hline Fuerza de la Industria & Peso & Ventaja Competitiva & Peso \\
\hline Potencial de crecimiento & 2 & Calidad del producto & -1 \\
\hline Disponibilidad tecnológica & 4 & Calidad del servicio & -2 \\
\hline Disponibilidad de maquinaria & 5 & Lealtad de clientes & -2 \\
\hline Negociación con proveedores & 5 & Integración vertical & -3 \\
\hline Acceso al mercado & 3 & Ciclo de vida del producto & -2 \\
\hline Estabilidad financiera & 3 & Competencia capacitada & -3 \\
\hline \multicolumn{1}{|c|}{ Promedio } & $\mathbf{3 , 6}$ & Promedio & $\mathbf{- 2 , 2}$ \\
\hline
\end{tabular}

Elaboración: Adaptado de [26]

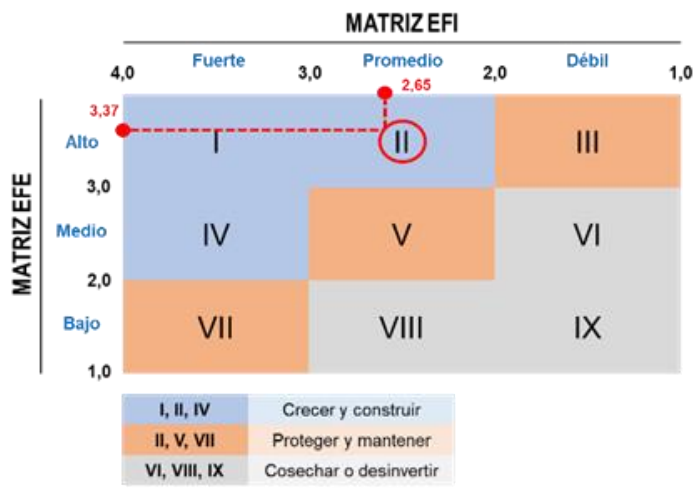

Fig. 9: Matriz Interna Externa (MIE) Elaboración: Propia

$1^{\text {sh }}$ LACCEI International Multiconference on Entrepreneurship, Innovation and Regional Development - LEIRD 2021: "Ideas to Overcome and Emerge from the Pandemic Crisis", Virtual Edition, December 9 - 10, 2021 


\section{- Matriz Interna - Externa}

La Figura 9 muestra la Matriz Interna Externa donde se consideraron los resultados de las matrices EFI y EFE. El resultado de intersección cuadrante II en referencia a "Crecer y construir" mediante estrategias para potenciamiento de los procesos, productos y servicios.

\section{- Matriz FODA}

Tras el análisis interno, externo y comercial, se establecen las iniciativas estratégicas por medio de la Matriz FODA:

$$
\text { TABLA VIII }
$$

ESTRATEGIAS DE LA MATRIZ FODA

$$
\text { Estrategias }
$$

Fortalezas - Oportunidades

E1: Motivación del personal con asignación de incentivos, capacitaciones, regalos, beneficios, línea de carrera, entre otros.

E2: Desarrollar un plan de marketing 4.0 con iniciativas para la interacción clientemarca.

E3: Explotar el contenido en base a las iniciativas ecológicas, responsabilidad social e innovación de la marca.

E4: Realizar ofertas, sorteo, promociones, asignación de beneficios adicionales por recomendaciones, menciones, compras consecutivas, etc.

\section{Debilidades - Oportunidades}

E5: Implementar medios digitales y redes sociales para venta (e-commerce), publicidad y promoción de productos, servicios y contenido sobre la cultura organizacional de la marca.

E6: Desarrollo de una venta al barrer de productos estancados en el almacén (para recuperar inversión y/u obtener ganancia pequeña).

E7: Solicitar financiamiento externo de agencias bancarias autorizadas por el Estado, con programas como Reactiva Perú o el fraccionamiento de deudas. Fortalezas - Amenazas

E8: Establecer política de costos y precios, mediante la investigación del entorno y la competencia, sin pérdida de la calidad de los productos.

E9: Diseñar un modelo de filtro para elección de proveedores locales con puntualización de criterios y/o características necesarias para la creación de alianzas estratégicas.

E10: Establecer alianzas estratégicas con marcas de productos alternativos (ropa, juguetes, artículos de aseo, etc.) para niños con posean redes sociales desarrolladas y/o con mayor posicionamiento.

\section{Debilidades - Amenazas}

E11: Utilizar plataformas TI gratuitas (debido a la falta de liquidez) como soporte para el control de inventarios, gestión comercial, gestión contable, gestión de personas, etc.

E12: Impulsar los medios de contacto digital one-to-one entre cliente y empresa por medio de redes sociales, correo electrónico, llamadas, etc. para la muestra del catálogo de productos, evitando así el contacto físico.

Elaboración: Propia

\section{- Matriz de la Gran Estrategia}

D’Niños se encuentra en el cuadrante IV, evidenciando la fuerte posición competitiva en relación al crecimiento lento del mercado debido a la coyuntura sanitaria. Entre las iniciativas

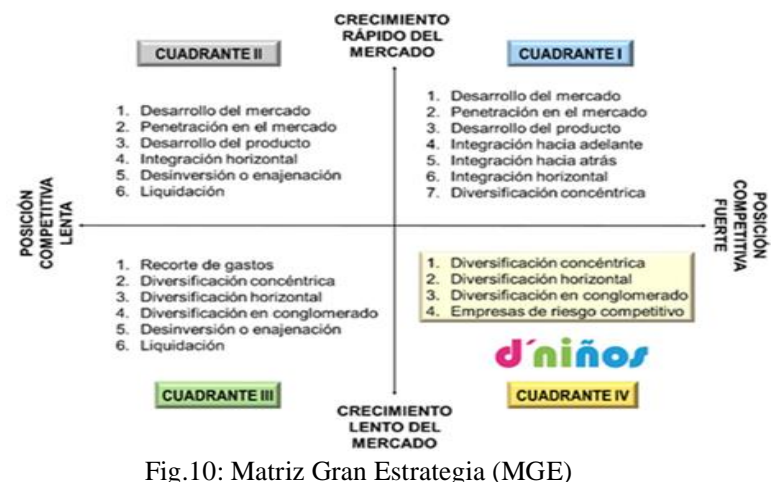

Fig.10: Matriz Gran Estrategia (MGE)

Elaboración: Propia posibles a emplear se encuentran la diversificación concéntrica, diversificación horizontal y la diversificación en conglomerado. Se busca que la organización surja en el mercado y se haga de conocimiento pleno, teniendo a su favor la amplia experiencia en el sector, teniendo siempre en cuenta el uso de la calidad como eje principal de desarrollo de productos y servicios.

\section{- Estrategias retenidas}

En la Tabla IX, se detallan 8 Estrategias alineadas a los 7 Objetivos organizacionales.

\begin{tabular}{|c|c|c|c|}
\hline \multicolumn{2}{|r|}{ Estrategia } & \multicolumn{2}{|r|}{ Objetivo } \\
\hline E1 & 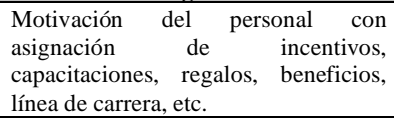 & O6 & $\begin{array}{l}\text { Aumentar la satisfacción } \\
\text { laboral en un } 65 \% \text { para el } \\
\text { trimestre } 3 \text { del } 2022 .\end{array}$ \\
\hline E2 & $\begin{array}{l}\text { Desarrollar un plan de marketing } 4.0 \\
\text { con iniciativas para el aumento de la } \\
\text { interacción cliente-marca. }\end{array}$ & 04 & $\begin{array}{l}\text { Aumentar la satisfacción de } \\
\text { los clientes en un } 25 \% \text { para } \\
\text { el trimestre } 3 \text { del } 2022 \text {. }\end{array}$ \\
\hline $\mathbf{E 3}$ & $\begin{array}{l}\text { Explotar el contenido en base a las } \\
\text { iniciativas ecológicas, responsabilidad } \\
\text { social e innovación de la marca. }\end{array}$ & O7 & $\begin{array}{l}\text { Aumentar el conocimiento } \\
\text { positivo de la marca un } 15 \% \\
\text { para el trimestre } 3 \text { del } 2022 .\end{array}$ \\
\hline E5 & $\begin{array}{l}\text { Implementar medios digitales y redes } \\
\text { sociales para la venta (e-commerce), } \\
\text { publicidad y promoción de los } \\
\text { productos, servicios y contenido sobre } \\
\text { la cultura organizacional de la marca }\end{array}$ & 01 & $\begin{array}{l}\text { Aumentar las ventas } \\
\text { efectuadas en un } 15 \% \text { para } \\
\text { el trimestre } 3 \text { del } 2022 .\end{array}$ \\
\hline E8 & $\begin{array}{l}\text { Establecer política de costos y precios, } \\
\text { mediante la investigación del entorno y } \\
\text { la competencia, sin pérdida de la } \\
\text { calidad de los productos }\end{array}$ & O5 & $\begin{array}{l}\text { Incrementar la probabilidad } \\
\text { de compra en un } 15 \% \text { para el } \\
\text { trimestre } 3 \text { del } 2022 .\end{array}$ \\
\hline E9 & $\begin{array}{l}\text { Diseñar un modelo de filtro para } \\
\text { elección de proveedores locales con } \\
\text { puntualización de criterios y/o } \\
\text { características necesarias para la } \\
\text { creación de alianzas estratégicas. }\end{array}$ & $\mathrm{O2}$ & $\begin{array}{l}\text { Aumentar la eficiencia del } \\
\text { servicio de ventas en un } \\
10 \% \text { para el trimestre } 3 \text { del } \\
2022 \text {. }\end{array}$ \\
\hline E10 & $\begin{array}{l}\text { Establecer alianzas estratégicas con } \\
\text { marcas de productos alternativos } \\
\text { (ropa, juguetes, artículos de aseo, etc.) } \\
\text { para niños con posean redes sociales } \\
\text { desarrolladas y/o con mayor } \\
\text { posicionamiento. }\end{array}$ & O3 & $\begin{array}{l}\text { Incrementar el número de } \\
\text { clientes nuevos en un } 10 \% \\
\text { para el trimestre } 3 \text { del } 2022 .\end{array}$ \\
\hline E12 & $\begin{array}{l}\text { Impulsar los medios de contacto digital } \\
\text { one-to-one entre cliente y empresa por } \\
\text { medio de redes sociales, correo } \\
\text { electrónico, llamadas, etc. para la } \\
\text { muestra del catálogo de productos, } \\
\text { evitando así el contacto físico. }\end{array}$ & $\mathrm{O2}$ & $\begin{array}{l}\text { Aumentar la eficiencia del } \\
\text { servicio de ventas en un } \\
10 \% \text { para el trimestre } 3 \text { del } \\
2022 \text {. }\end{array}$ \\
\hline
\end{tabular}

\section{ESTRATEGIAS RETENIDAS}

Elaboración: Propia

\section{Fase 3: Evaluación y seguimiento estratégico \\ C.1 Control estratégico}

\section{- Cuadro de Mando Integral}

Como etapa final, se estableció el Cuadro de Mando Integral donde se puntualizan los indicadores de control, las fórmulas y las metas que se buscan alcanzar con el desarrollo de las estrategias.

TABLA X

\begin{tabular}{|c|c|c|c|c|c|c|c|}
\hline \multirow{2}{*}{ Perspectiva } & \multirow{2}{*}{ Objetivos } & \multirow{2}{*}{ Indicador } & \multirow{2}{*}{ Unidad } & \multirow{2}{*}{ Fórmula } & \multicolumn{3}{|c|}{ Meta } \\
\hline & & & & & Mal & Regular & Bien \\
\hline \multirow[t]{2}{*}{ Financiera } & \multirow{2}{*}{$\begin{array}{l}\text { Aumentar las ventas } \\
\text { efectuadas }\end{array}$} & $\begin{array}{l}\text { Índice de evolución de } \\
\text { ventas }\end{array}$ & $\%$ & $\frac{\# \text { pares vendidos en el periodo } 2 \text { - \# pares vendidos en el periodo } 1}{\text { Total de pares vendidos en el periodo } 1} \times 100$ & $<35 \%$ & $35 \%-60 \%$ & $>=60 \%$ \\
\hline & & Volumen de ventas & $\mathrm{N}^{\circ}$ & $\mathrm{X}=\Sigma\left[\mathrm{N}^{\circ}\right.$ de pares vendidos durante el periodo $]$ & $<1500$ & $1500-3500$ & $>=3500$ \\
\hline
\end{tabular}

CUADRO DE MANDO INTEGRAL

$1^{\text {sh }}$ LACCEI International Multiconference on Entrepreneurship, Innovation and Regional Development - LEIRD 2021: "Ideas to Overcome and Emerge from the Pandemic Crisis", Virtual Edition, December 9 - 10, 2021. 


\begin{tabular}{|c|c|c|c|c|c|c|c|}
\hline & & $\begin{array}{l}\text { Tasa de crecimiento de } \\
\text { ingresos }\end{array}$ & $\%$ & $\frac{\text { Total de ingresos periodo } 2 \text { - Total de ingresos periodo } 1}{\text { Total de ingresos periodo } 1} \times 100$ & $<35 \%$ & $35 \%-50 \%$ & $>=50 \%$ \\
\hline \multirow{6}{*}{ Clientes } & \multirow{2}{*}{$\begin{array}{l}\text { Aumentar la satisfacción } \\
\text { del cliente }\end{array}$} & $\begin{array}{l}\text { Índice de satisfacción } \\
\text { del cliente respecto al } \\
\text { producto }\end{array}$ & $\%$ & $\begin{array}{l}\text { \# Cuestionarios con "Totalmente de acuerdo" y "De acuerdo" } \\
\text { en satisfacción por producto } \\
\text { \#Total de encuestados }\end{array}$ & $<45 \%$ & $45 \%-70 \%$ & $>=70 \%$ \\
\hline & & $\begin{array}{c}\text { Índice de satisfacción } \\
\text { del cliente respecto al } \\
\text { servicio }\end{array}$ & $\%$ & $\begin{array}{c}\text { \# Cuestionarios con "Totalmente de acuerdo" y "De acuerdo" } \\
\text { en satisfacción por servicio } \\
\text { \#Total de encuestados }\end{array}$ × 100 & $<60 \%$ & $60 \%-85 \%$ & $>=85 \%$ \\
\hline & \multirow{2}{*}{$\begin{array}{l}\text { Incrementar la } \\
\text { probabilidad de compra }\end{array}$} & $\begin{array}{l}\text { Índice de probabilidad } \\
\text { de compra según lugar }\end{array}$ & $\%$ & $\begin{array}{l}\text { \# Cuestionarios con "Totalmente de acuerdo" y "De acuerdo" } \\
\text { en probabilidad de compra según lugar } \\
\text { \#Total de encuestados }\end{array}$ & $<45 \%$ & $45 \%-65 \%$ & $>=65 \%$ \\
\hline & & $\begin{array}{l}\text { Índice de probabilidad } \\
\text { de compra según precio }\end{array}$ & $\%$ & $\begin{array}{c}\text { \# Cuestionarios con "Totalmente de acuerdo" y "De acuerdo" } \\
\text { en probabilidad de compra según precio }\end{array}$ & $<45 \%$ & $45 \%-65 \%$ & $>=65 \%$ \\
\hline & $\begin{array}{l}\text { Incrementar el número } \\
\text { de clientes nuevos }\end{array}$ & $\begin{array}{c}\text { Índice de atracción de } \\
\text { clientes }\end{array}$ & $\%$ & $\frac{\text { \# Cuestionarios con respuesta "SI" es primera compra }}{\text { \#Total de encuestados }} \times 100$ & $<20 \%$ & $20 \%-50 \%$ & $>=50 \%$ \\
\hline & $\begin{array}{c}\text { Aumentar el } \\
\text { conocimiento positivo } \\
\text { de la marca }\end{array}$ & $\begin{array}{l}\text { Índice de identidad de } \\
\text { marca }\end{array}$ & $\%$ & $\begin{array}{c}\text { \# Cuestionarios con "Totalmente de acuerdo" y "De acuerdo" } \\
\text { en aspecto de identidad de marca } \\
\text { \#Total de encuestados }\end{array}$ & $<55 \%$ & $55 \%-75 \%$ & $>=75 \%$ \\
\hline Procesos & $\begin{array}{l}\text { Aumentar la eficiencia } \\
\text { del servicio de ventas }\end{array}$ & $\begin{array}{l}\text { Índice de eficiencia de } \\
\text { ventas }\end{array}$ & $\%$ & $\frac{\mathrm{N}^{\circ} \text { total de ventas generadas }-\mathrm{N}^{\circ} \text { de reclamos }}{\mathrm{N}^{\circ} \text { total de ventas generadas }} \times 100$ & $<70 \%$ & $70 \%-90 \%$ & $>=90 \%$ \\
\hline \multirow{2}{*}{$\begin{array}{l}\text { Aprendizaje y } \\
\text { crecimiento }\end{array}$} & \multirow{2}{*}{$\begin{array}{l}\text { Aumentar la satisfacción } \\
\text { laboral }\end{array}$} & $\begin{array}{c}\text { Índice de objetivos } \\
\text { alcanzados por } \\
\text { colaborador }\end{array}$ & $\%$ & $\frac{\mathrm{N}^{\circ} \text { total de objetivos logrados }}{\mathrm{N}^{\circ} \text { total de objetivos planteados }} \times 100$ & $<80 \%$ & $80 \%-95 \%$ & $>=95 \%$ \\
\hline & & $\begin{array}{c}\mathrm{N}^{\circ} \text { de beneficios } \\
\text { brindados }\end{array}$ & $\mathrm{N}^{\circ}$ & $\mathrm{X}=\Sigma\left[\mathrm{N}^{\circ}\right.$ de beneficios brindados por colaborador $]$ & $<3$ & $4-6$ & $>7$ \\
\hline
\end{tabular}

Elaboración: Propia

\section{DISCUSIONES}

La investigación tuvo como propósito diseñar un modelo de gestión comercial para la recordación de marca de la pyme Calzado D'Niños en la ciudad de Trujillo en el año 2021, tomando como base a [25], quien determina que el análisis del entorno interno y externo organizacional es primordial para determinar factores claves de consideración en el planteamiento de iniciativas estratégicas, basándose en la visión y objetivos, para su cumplimiento óptimo.

El estudio realizado por [29] sostiene que la implementación de un modelo estratégico de gestión influye significativamente en la empresa en estudio, habiendo obtenido resultados positivos en la evaluación de desempeño bajo indicadores. El estudio genera un antecedente de valor que es sustento a la presente para su próxima formulación.

La recolección de información para el diseño del modelo de gestión comercial se ejecutó mediante encuestas a 40 clientes donde se determinaron aspectos sobre la edad promedio, género, nivel de recomendación del negocio, diferenciación de la competencia, nivel de confianza, nivel de satisfacción, calidad del producto y servicio, recomendaciones, entre otros, para reconocer lineamientos de mejora y potenciamiento y consideración en las estrategias. Ello coincide con [30] [31] quienes analizaron el nivel de posicionamiento de la empresa en estudio, tomando en cuenta directivas como la satisfacción del cliente, nivel de consumo, grado de fidelización, etc. cuyos resultados fueron el sustento de las estrategias planteadas.

El diagnóstico situacional fue ejecutado en base al análisis interno y externo con el uso de la matriz EFI, EFE, AMOFHIT, 5 Fuerzas de Porter, etc., coincidente con [32], se consideró también dichos instrumentos para el reconocimiento global del entorno de la organización y reconocer las fortalezas, debilidades, amenazas y oportunidades. [33] usó estas herramientas, permitiendo concluir que, sin el estudio interno y externo, no se puede conseguir una estabilidad empresarial. Ambos estudios, trasladan el análisis situacional a la matriz FODA, donde se plantean las estrategias.

Ante ello, las iniciativas para la recordación de marca establecidas sostienen que Calzado D'Niños debe constituir una imagen de responsabilidad social compartida haciendo uso del marketing 4.0 a través de medios digitales y potenciar las ventas en redes sociales, actualmente en auge debido a la coyuntura sanitaria, coincidiendo con [34] quien sostiene que vender en tiempos de pandemia COVID-19 implica adaptarse a las preocupaciones de los clientes, el confinamiento parcial y las limitaciones, cambios de paradigmas y sobre todo, nuevos hábitos de consumo, flexibilizando los canales de venta y marketing, permitiendo así la mantención a flote de la pyme. Así mismo, se propone velar por la satisfacción laboral como base para obtener mejores resultados tanto en cuanto a los servicios de venta y a los productos, coincidiendo con [35] quien considera al compromiso de los colaboradores como recurso vital para la mejora organizacional.

Finalmente, se planteó el Cuadro de Mando Integral que se sustenta en [36] habiendo demostrado su absoluta eficacia, demostrando que se pueden generar cambios reales y un impacto positivo a través del cumplimiento de las metas.

\section{CONCLUSIONES}

El modelo de gestión comercial para la recordación de marca de la pyme Calzado D'Niños permitió integrar las necesidades de la organización con factores claves de éxito internos y externos, mediante prácticas estructuradas y el planteamiento de iniciativas estratégicas. El modelo teórico fue diseñado de manera funcional para el logro óptimo de los objetivos, para lo que se dividió de 3 fases: Formulación y planeamiento estratégico donde se analizó la situación actual de la organización, Diseño estratégico donde se establecieron los objetivos y las iniciativas estratégicas y, finalmente, Evaluación y seguimiento donde se desarrolló el Cuadro de Mando Integral con los indicadores de evaluación de desempeño.

El diagnóstico situacional de Calzado D’Niños se basó en la cultura organizacional, análisis interno y externo en lo que se concluye que el negocio se encuentra en una fase de estancamiento por la disminución de las ventas debido a la coyuntura por la COVID-19. La evaluación de factores internos denotó que la empresa posee puntos fuertes que afectan su desempeño y las fortalezas no son explotadas al 100\% para contrarrestar lo negativo. Por otro lado, la evaluación de los factores externos evidenció que se aprovechan las oportunidades en gran magnitud, pero las amenazas afectan de manera drástica los resultados.

El análisis de los procesos comerciales se ejecutó por medio de la técnica de la observación y encuestas a 40 clientes donde se determinó que sólo el 52,5\% se identifican con la

$1^{\text {sh }}$ LACCEI International Multiconference on Entrepreneurship, Innovation and Regional Development - LEIRD 2021: “Ideas to Overcome and Emerge from the Pandemic Crisis", Virtual Edition, December 9 - 10, 2021. 
marca, sustentándose en la buena y sólida cartera de clientes fieles existentes. Los resultados permitieron reconocer que la afección de la COVID-19 a las ventas y continuidad del negocio surgieron debido a la falta de uso de medios digitales para la promoción y comercialización, falta de innovación en cuanto a procesos sin implantación de estrategias de mejora, impactando así en el poco reconocimiento de la marca.

Las 12 estrategias preestablecidas con una selección final de 8 como "Retenidas" (Motivación del personal, plan de marketing 4.0, contenido en base a responsabilidad social, medios digitales, política de costos, filtro de elección de proveedores, alianzas estratégicas, contacto digital one-to-one), se enlazan directamente con los 7 objetivos estratégicos organizativos, lo que permite reconocer el impacto positivo que su implementación brindaría a la organización.

Se establecieron 12 indicadores de evaluación en el Cuadro de Mando Integral alineados a los 7 objetivos y 4 Perspectivas (Cliente, Procesos Internos, Finanzas y Aprendizaje y Crecimiento) para medir el nivel de cumplimiento del proceso de implementación. Con ello, se pueden puntualizar los escenarios meta con una clasificación de bueno, regular o malo en referencia a los resultados cuantitativos por cada indicador.

El impacto económico concluyó en una inversión de S/76.530 y un costo anual de S/71.020 con VAN positivo de S/173.598,16 indicando la inversión puede ser sustentada a través de los ingresos: por otro lado, el TIR obtuvo un resultado de $87 \%$ superior a la tasa utilizada y un índice de beneficio costo $\mathrm{B} / \mathrm{C}$ de S/1.58 que indica que se obtiene una ganancia de 58 céntimos por cada sol invertido.

\section{REFERENCIAS}

[1] Ibarra, M., González, L \& Demuner, M. (2017). Business competitiveness in the small and medium-sized enterprises of the manufacturing sector in Baja California. Estudios Fronterizos, 18(35). https://doi.org/10.21670/ref.2017.35.a06

[2] Cortez, V. (2016). ¿Pueden las Micro, Pequeñas y Medianas Empresas superar sus principales problemáticas a través de herramientas de Gestión? Gestión de las Personas y Tecnología, 9(27), 10.

[3] Cepeda, S., Marín, B., \& Velásquez, L. (2017). Análisis evaluativo a los procesos de marketing en la internacionalización de las pequeñas y medianas empresas de alimentos de Medellín. Estudios Gerenciales, 33(144), 271-280. https://doi.org/10.1016/j.estger.2017.06.006

[4] Ponce, J. (2017). La gestión comercial y su influencia en el crecimiento de las PYMES hoteleras de Manabí. ECA Sinergia, 8(2), 54-68.

[5] Campos, M. \& Moreira, L. (2017). Gestión comercial y posicionamiento en el mercado de la procesadora Kasama Chips de la ciudad de Santo Domingo. https://dspace.uniandes.edu.ec/handle/123456789/6368

[6] Ortegón, L. (2010). Panorama actual de los métodos de medición de marcas y valor de marca desde la orientación al consumidor. Poliantea, 6(11), 8.

[7] Martínez, D., \& Milla, A. (2005). La elaboración del plan estratégico y su implantación a través del cuadro de mando integral (1. ${ }^{\mathrm{a}}$ ed.). Diaz De Santos. https://www.editdiazdesantos.com/libros/martinez-pedros-daniella-elaboracion-del-plan-estrategico-y-su-implantacion-a-traves-delcuadro-de-mando-integral-L03007121401.html

[8] Ohmae, K. (2004). La mente del estratega. McGraw-Hill Interamericana de España S.L.

[9] Henderson, B. D. (1989). The Origin of Strategy. Harvard Business Review. https://hbr.org/1989/11/the-origin-of-strategy

[10]Sharán, M. (2019). Estrategias de fidelización de clientes a través de internet. Editorial Elearning, S.L.

[11]Palco 23. (2021, marzo 10). Adidas salva el año de la pandemia y cae sólo un $16 \%$ en 2020 . https://www.palco23.com/equipamiento/adidas-salva-elano-de-la-pandemia-y-cae-solo-un-16-en-2020.html

[12]World Footwear. (2020). Anuario Mundial del Calzado 2020. https://www.worldfootwear.com/yearbook/the-world-footwear-2020Yearbook/214.html?utm_source=Site\&utm_medium=RevistadelCalzado \&utm_campaign=Yearbook
[13]Gestión Noticias. (2017, junio 8). Perú produce más de 50 millones de pares de calzado de cuero al año y eso atrae a Brasil. Gestión. https://gestion.pe/economia/peru-produce-50-millones-pares-calzadocuero-ano-atrae-brasil-136833-noticia/

[14]Fuster, B., Martínez, C., \& Pardo, G. (2009). Las estrategias de competitividad de la industria del calzado ante la globalización. Revista de estudios regionales, $86,71-96$.

[15]Diario Correo. (2020, septiembre 22). 50\% de sector calzado inactivo. Diario Correo. https://diariocorreo.pe/edicion/la-libertad/50-de-sectorcalzado-inactivo-950016/

[16]Otzen, T., \& Manterola, C. (2017). Técnicas de Muestreo sobre una Población a Estudio. International Journal of Morphology, 35(1), 227-232. https://doi.org/10.4067/S0717-95022017000100037

[17]Guevara, J., \& Medina, J. (2012). Modelo de Gestión Administrativa para el Gobierno de la Parroquia de Yaruquí, Cantón Quito, Provincia de Pichincha. http://www.dspace.uce.edu.ec/handle/25000/1220

[18]Martínez, Á. (2013). Desarrollo y definición de un modelo de gestión como paso previo al a innovación empresarial. Calidad: Revista mensual de la Asociación Española para la Calidad, 1, 4.

[19]Quinn, R. E. (1994). Maestría en la gestión de organizaciones: Un modelo operativo de competencias. Ediciones Díaz de Santos.

[20]De Borda, F. (2008). Sistematización de la Función Comercial. Cómo integrar con éxito su estrategia corporativa. Netbiblo.

[21]Herrero, J. (2012). Administración, gestión y comercialización en la pequeña empresa ( $3 \mathrm{a}$ ed.). Editorial Paraninfo.

[22]Clarke, M., Cisneros, Y., \& Paneca, Y. (2018). Gestión Comercial: Diagnóstico del atractivo y rentabilidad del punto de ventas. Ciencias Holguín, 24(4), 11-25. https://www.redalyc.org/jatsRepo/1815/181557161002/index.html

[23]Morales, Á. (2013). Gestión Comercial, en un Mundo Globalizado por Alvaro Morales Fernández. TusLibros.Com. https://www.tuslibros.com/ebook/Gestion-Comercial-en-un-MundoGlobalizado

[24]Stanton, W., Etzel, M., y Walker, B. (2009). Fundamentos de Marketing. (13ª . Ed.). México: Mc Graw Hill

[25]D’Alessio, F. (2015). El Proceso Estratégico: Un Enfoque de Gerencia. (3. ${ }^{a}$ ed.). Juárez, España: Pearson.

[26]Chiavenato, I. y Sapiro, A. (2011). Planeación estratégica: Fundamentos y Aplicaciones. (2. ${ }^{\mathrm{a}}$ ed.). México D.F., México: McGraw-Hill.

[27]Canaval, A. (2015). Evaluación del posicionamiento de la empresa Sextinvalle LTDA. en la ciudad de Cali año 2015.154. http://hdl.handle.net/10614/8555

[28]Colmenares, O., Schlesinger, W., y Saavedra, J. (2009). Conocimiento de marca: una revisión teórica. Ciencia y tecnología administrativa, 81-117

[29]Deza, J., Florián, O., \& Zanabria, P. (2020). Modelo Estratégico y su Impacto en la Gestión Comercial de una Empresa PYME del Sector Automotriz. VirtualEdition/meta/FP164.html

http://laccei.org/LACCEI2020-

[30]Bravo, E., Guevara, D., \& Deza, J. M. (2020). Modelo Estratégico y su Influencia en el Posicionamiento de la Constructora y Consultora José Abiel SAC, Jaén, 2018. http://laccei.org/LACCEI2020VirtualEdition/meta/FP129.html

[31]Cercado, M., \& Taboada, K. (2019). Análisis del posicionamiento de la marca Europa Kids de la empresa comercial Tami S.R.L. Chiclayo 2019. Universidad Católica Santo Toribio de Mogrovejo - USAT. http://tesis.usat.edu.pe/handle/20.500.12423/2176

[32]Lizarzaburu, J. M., \& Lizarzaburu, L. M. (2016). Formulación de un modelo estratégico y su impacto en la gestión del cliente en la empresa de transportes Cargum Express S.R.L. Universidad Privada del Norte. https://repositorio.upn.edu.pe/handle/11537/11107

[33]Robles, D., \& Carreño, N. (2020). Plan estratégico para lograr la sostenibilidad de la escuela de conducción Sportmancar. Polo del Conocimiento: Revista científico - profesional, 5(3), 519-540. https://doi.org/10.23857/pc.v5i3.1348

[34]Labrador, H. E., Suarez, J. J., \& Suarez, S. A. (2020). Marketing en tiempos de crisis generado por la COVID-19. Revista Espacios, 41(42). https://doi.org/10.48082/espacios-a20v41n42p17

[35]Ochoa, S., Medina, C., Santamaría, L., Ramírez, D., Paramo, E., \& Ochoa, N. (2020). Reto de las mipymes para incursionar en el marketing digital en tiempos de COVID-19. Revista Humanismo y Sociedad, 8(2), 132-145. https://dialnet.unirioja.es/servlet/articulo?codigo $=7716810$

$1^{\text {sh }}$ LACCEI International Multiconference on Entrepreneurship, Innovation and Regional Development - LEIRD 2021: "Ideas to Overcome and Emerge from the Pandemic Crisis", Virtual Edition, December 9 - 10, 2021. 